\title{
ДЕНДРОХРОНОЛОГИЯ ЭЛЕМЕНТНОГО СОСТАВА КАК ПЕРСПЕКТИВНОЕ НАПРАВЛЕНИЕ БИОГЕОХИМИИ
}

\author{
Академик Е. А. Ваганов, А. М. Грачев, В. В. Шишов, \\ И. П. Панюшкина, С. У. Левитт, А. А. Кнорре, Е. П. Чебыкин, О. В. Меняйло
}

Поступила в редакцию

\begin{abstract}
Химические элементы, связанные с ионным составом цитоплазмы клеток, являются важнейшими компонентами высших растений. Ори обеспечивают разнообразные процессы жизнедеятельности растений, связанные с клеточной энергетикой, функционированием большого числа ферментов и др. [1]. Поступая из почвы, химические элементы выполняют свои функции в растении и с его отмиранием замыкают важнейшие биогеохимические циклы [2]. Долгоживущие древесные растения являются элементами биогеохимических циклов с разными характеристическими временами: от года до столетий. Ежегодно формируя годичные кольца, древесные растения с одной стороны, фиксируют текущие климатические условия роста, с другой - накапливают информацию о длительных изменениях в окружающей их среде [3]. Клетки древесины созревают в течение сезона, а после отмирания функционируют как система водопроводящих сосудов, состоящих из одревесневших стенок. Химические элементы, жестко связанные с веществом клеточных стенок древесины и сохраняющие эту связь на протяжении многих десятилетий, являются, таким образом, потенциальным источником информации о процессах и факторах, их определяющих, которые имели место в период созревания клеток древесины.
\end{abstract}

В данной работе впервые представлены изменения важнейших элементов ( $\mathrm{P}, \mathrm{K}, \mathrm{Ca}, \mathrm{Mg}, \mathrm{Sr}, \mathrm{Ba}$, $\mathrm{Cl}, \mathrm{Si})$ с 1300 по 2000 г. н.э. в годичных кольцах лиственницы Гмелина (Larix gmelinii Rupr.) полуострова Таймыр (полярная граница лесной расти-

Сибирский федеральный университет, Красноярск Институт леса им. В.Н. Сукачева

Сибирского отделения Российской Академии наук, Красноярск

Аризонский университет, Тусон, США

Лимнологический институт

Сибирского отделения Российской Академии наук, Иркутск тельности, $72^{\circ}$ с.ш.). В данной работе рассматриваются элементы, представляюшие наибольший интерес, хотя метод позволил определить в общей сложности концентрации 40 элементов. Имеется множество публикаций по элементному составу годичных колец на коротких временных участках, однако потенциал использования сигнала элементов для длительных реконструкций условий палеосреды остается нераскрытым. Столь длительная дендрохимическая летопись по элементам получена впервые. Условия произрастания деревьев на многолетнемерзлотной почве п-ова Таймыр жестко лимитированы температурой. Образцы деревьев (спилы) были собраны в 2006 г. Датировка спилов осуществлена по длительной хронологии, ранее полученной для этого района [4]. Собственный возраст деревьев был в пределах 350-400 лет, для каждого календарного периода измеряли 3-6 образцов из разных спилов. Покрытие временного интервала в 700 лет было обеспечено образцами как с живых, так и с очень хорошо сохранившихся отмерших деревьев. Всего был проанализирован 351 образец из 16 деревьев. Разовая проба включала 5-летний или 10-летний период роста (5 или 10 календарно датированных годичных колец). Химический анализ проводили методом масс-спектрометрии с индукционно-связанной плазмой (ICP-MS) на квадрупольном спектрометре Agilent 7500ce. Измерения проводили в средах, полученных путем растворения древесных образцов в концентрированной азотной кислоте и их последующего разбавления водой. Метод обработки древесных образцов, их растворения, последующей пробоподготовки и измерения подробно изложен в работе [5].

Многолетние средние величины, а также пределы колебаний концентраций элементов в древесных образцах приведены в табл. 1. Содержание в древесине $\mathrm{K}$ и Са-элементов ионного состава цитоплазмы максимальное. Минимальное содержание характерно для Ва и $\mathrm{Sr}$-химических аналогов Са и $\mathrm{Mg}$. По характеру временной изменчивости все исследованные элементы четко разделя- 
Таблица 1. Средние и экстремальные значения концентрации химических элементов в древесине годичных колец лиственницы за весь исследованный временной интервал (700 лет)

\begin{tabular}{c|c|c}
\hline $\begin{array}{c}\text { Химический } \\
\text { элемент }\end{array}$ & $\begin{array}{c}\text { Средняя концен- } \\
\text { трация, pрm }\end{array}$ & $\begin{array}{c}\text { Пределы колебаний } \\
\text { концентрации, pрm }\end{array}$ \\
\hline $\mathrm{Ca}$ & 708 & $210-2200$ \\
$\mathrm{~K}$ & 306 & $70-1100$ \\
$\mathrm{Cl}$ & 242 & $40-600$ \\
$\mathrm{Mg}$ & 223 & $50-520$ \\
$\mathrm{Si}$ & 133 & $80-190$ \\
$\mathrm{P}$ & 34 & $6-200$ \\
$\mathrm{Ba}$ & 11 & $2-130$ \\
$\mathrm{Sr}$ & 4 & $1-9$ \\
\hline
\end{tabular}

ются на три группы. Первую группу образуют К и $\mathrm{P}$, особенность динамики которой - относительно стабильный уровень концентрации на протяжении периода от 1300 до 1950 гг. и затем резкое увеличение концентрации в годичных кольцах лиственниц, сформированных в период после 1950 г. (рис. 1). Вторую группу образуют щелочноземельные элементы (Ca, $\mathrm{Mg}, \mathrm{Sr}, \mathrm{Ba})$, по химическим свойствам близкие друг к другу. По величине средней концентрации в клеточных стенках древесины содержание элементов убывает от Са к
$\mathrm{Sr}:[\mathrm{Ca}]>[\mathrm{Mg}]>[\mathrm{Ba}]>[\mathrm{Sr}]$. Временная динамика этих элементов однотипна: постепенное уменьшение концентрации в годичных кольцах от прошлого к современности (рис. 2). Третью группу образуют $\mathrm{Cl}$ и $\mathrm{Si}(\mathrm{Cl} / \mathrm{Si} \sim 2)$, временная динамика которых тесно коррелирует (рис. 3). Следует отметить, что $\mathrm{Cl}$ и $\mathrm{Si}$ формально отнесены к одной группе, хотя характеризуются совершенно разными свойствами. Представляет интерес выявить природу тесной корреляции между этими элементами.

Рассмотрим возможные причины выявленной временной динамики в трех выделенных группах. Резкое (на порядок) и статистически значимое $(P<0.001)$ увеличение концентраций Р и К в древесных кольцах начиная с 1950 г по настоящее время не может быть случайным (рис. 1). N, P и K главные макроэлементы, ограничивающие рост растений, причем их действие взаимосвязано [6]. В криогенных почвах основным ограничивающим питательным элементом является азот N [7]. Доступность К и Р может изменяться при изменении кислотности почв [8], однако не в 10 раз, как отмечено для древесных колец в данной работе. Такое резкое увеличение концентраций К и Р в годичных кольцах может быть связано с увеличением потребления деревьями этих элементов как отклик на увеличение азотсодержащих кислотных осадков и, как следствие, увеличение содержания азота в почве, что наблюдается повсемест-

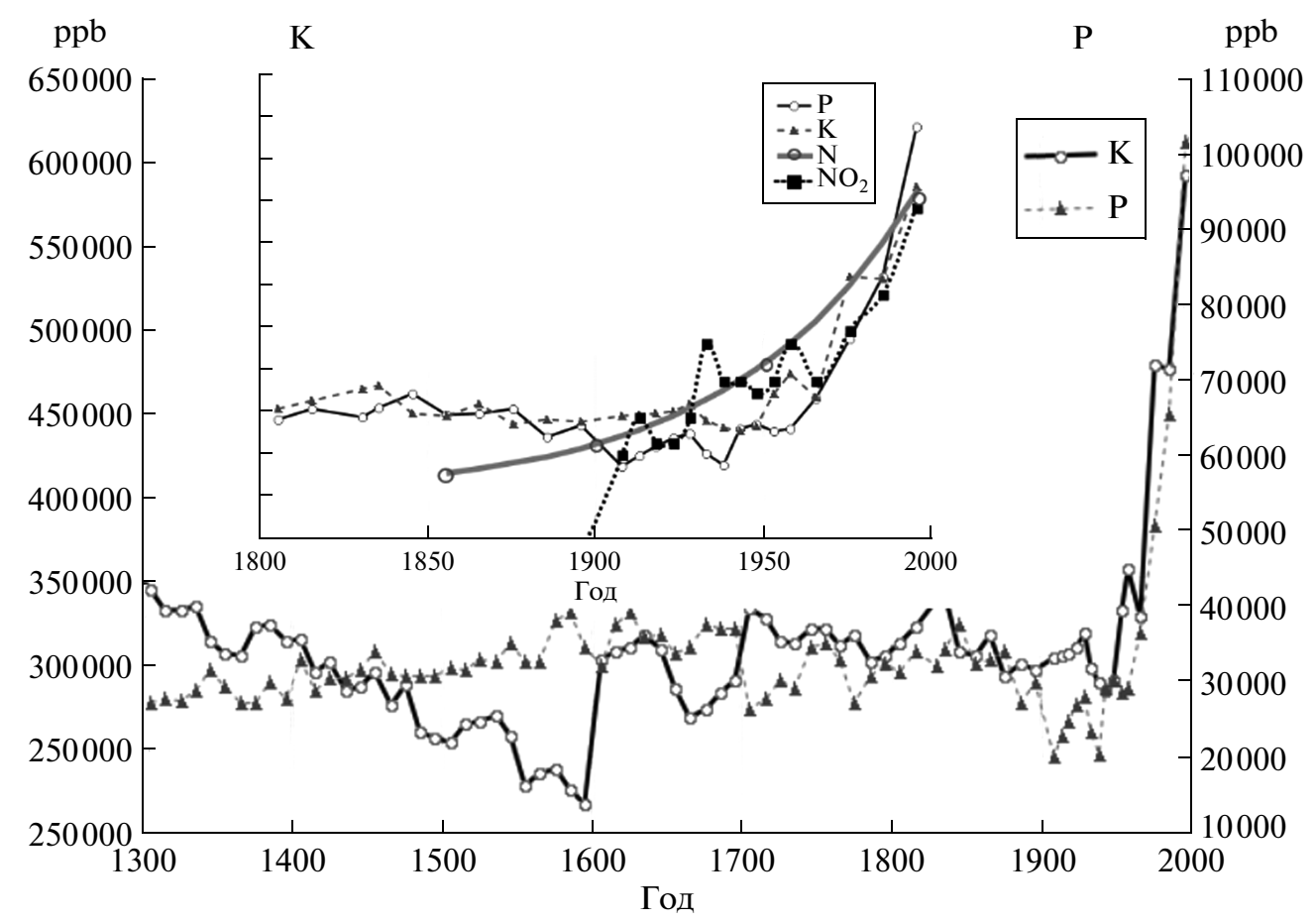

Рис. 1. Временная изменчивость концентрации К и Р в годичных кольцах (в ед. ppb). На врезке сопоставление динамики К и Р с содержанием активного азота $\mathrm{N}$ в биосфере и атмосферного $\mathrm{NO}_{2}$ за последние 150 лет и 100 лет соответственно по данным [14]. 
Концентрация элементов, отн. ед.
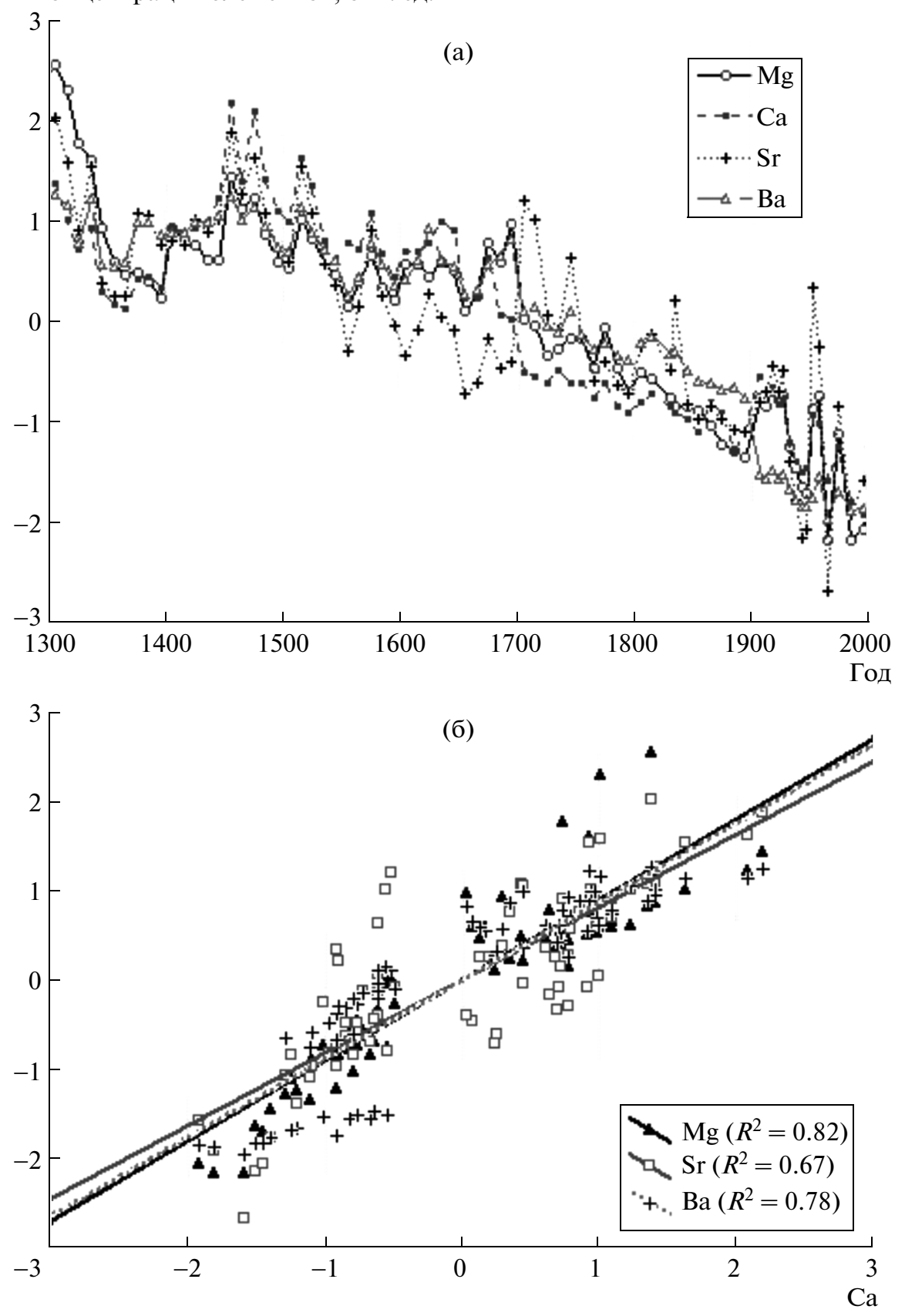

Рис. 2. Временная изменчивость $\mathrm{Ca}, \mathrm{Mg}$, Ва и $\mathrm{Sr}$ в годичных кольцах (а) и корреляционные диаграммы концентраций этих элементов по отношению к Са (б). Для удобства сравнения концентрации приведены к относительным величинам, т.е. разности между измеренным и многолетним средним значениями, отнесенной к общей дисперсии изменчивости концентрации химического элемента: $Z_{\text {scores }}=\frac{\left[C_{\text {current }}\right]-\left[C_{\text {average }}\right]}{\sigma[\mathrm{C}]}$.

но из-за роста промышленных выбросов (рис. 1). Отметим, что отношение $\mathrm{P}$ : К составляло 1 : 10 за основной исследуемый период (1300-1950 гг.) и при росте концентраций обоих элементов в период 1950-2000 гг. отношение повысилось до $1: 5$, что говорит о преимущественном накоплении Р по сравнению с К при уменьшении азотного ли- митирования в почве. Это указывает на действие определенных механизмов, осуществляющих баланс между основными макроэлементами как при поглощении их из почвы, так и при фиксации их в структурах клеточных стенок ксилемы [9].

Концентрация $\mathrm{Ca}, \mathrm{Mg}, \mathrm{Sr}$ и Ва за последние 700 лет уменьшилась в древесине лиственниц прак- 

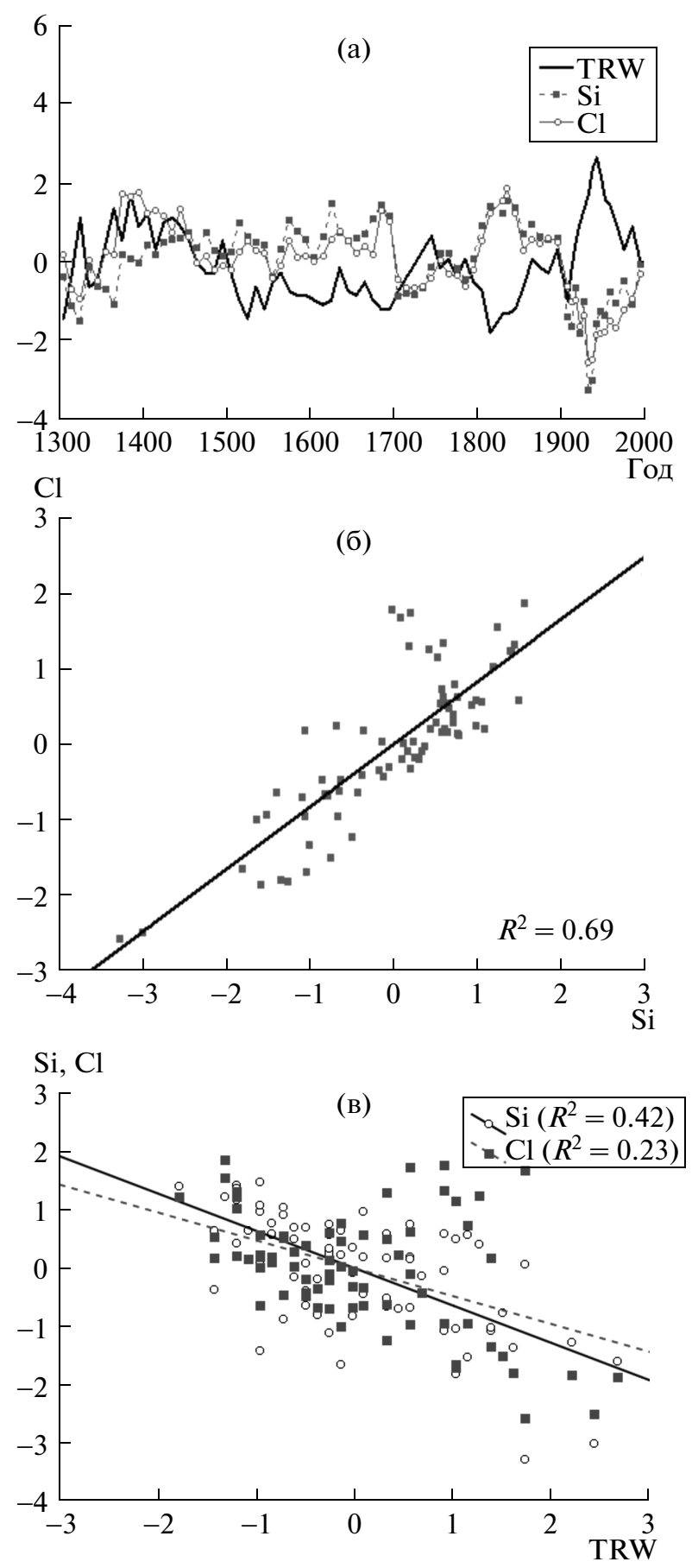

Рис. 3. Временная изменчивость концентрации Si и $\mathrm{Cl}$ в годичных кольцах в сопоставлении с пятилетней сглаженной древесно-кольцевой хронологией (a), корреляционные диаграммы между $\mathrm{Si}$ и $\mathrm{Cl}$ (б), а также между $\mathrm{Si}, \mathrm{Cl}$ и радиальным приростом деревьев (в) за весь период измерений. TRW - стандартная древесно-кольцевая хронология, нормированная к среднему значению и среднеквадратичному отклонению.

тически в три раза (рис. 2). Эти изменения не обусловлены возрастом деревьев, поскольку для разных временных интервалов измеряли образцы дре- весины как старовозрастных, так и более молодых деревьев. Са и $\mathrm{Mg}$ - основные зольные элементы стволовой древесины, выполняющие функцию цементирования клеточных стенок и участвующие в ионном обмене клеток. В почве катионы $\mathrm{Ca}^{2+}, \mathrm{Mg}^{2+}, \mathrm{Sr}^{2+}$ являются основными обменными ионами почвенного поглощающего комплекса (ППК). В последние сто лет отмечается обеднение ППК большинства типов почв этими катионами, что выявлено как на основе изучения почвенных образов, отобранных в разное время [10], так и по данным их содержания в годичных кольцах древесных растений [11]. Главная причина обеднения ППК - снижение рН почв вследствие выпадения кислотных осадков и замещение катионов $\mathrm{Ca}^{2+}$ и $\mathrm{Mg}^{2+}$ в ППК катионами $\mathrm{Al}^{3+}$ [12]. Однако обнаруженная тенденция постепенного уменьшения концентраций $\mathrm{Ca}, \mathrm{Mg}, \mathrm{Sr}$ и Ва за последние 700 лет свидетельствует, что увеличение кислотности почв и обеднение ППК криогенных почв Таймыра катионами этих элементов не связано с кислотными осадками, которые наблюдаются лишь в последние 50-70 лет. Возможная причина, интересная для перспективы биогеохимических исследований, - это конкуренция между древесным и напочвенным покровом за макроэлементы. Известно, что в условиях лесотундры прирост запаса (и биомассы) напочвенного покрова (мхи, лишайники, кустарники) значительно превышает таковой древесного полога [13], и по мере развития древостоя, конкуренция за макроэлементы между двумя основными компонентами экосистемы может значительно возрастать, особенно при ограниченном поступлении их из слоя сезонного оттаивания почвы.

Наконец, нами выявлена достоверная отрицательная корреляция между концентрацией хлора и кремния и относительным радиальным приростом древесных растений в условиях лесотундры (рис. 3). Ранее было показано, что относительный прирост древесных растений в этих условиях значимо определяется изменениями летней температуры [4]. Кремний как элемент участвует в структурном формировании клеточных стенок древесины, а, значит, его содержание должно меняться в зависимости от внешних условий, влияющих на процессы продукции и созревания трахеид (утолщений клеточных стенок). Повышение температуры ускоряет процессы продукции клеток древесины, что при ограниченном потоке кремния из почвы уменьшает его концентрацию в формирующихся клетках древесины. Роль хлора остается до сих пор функционально неясной. Однако то, что хлор является индикатором внешнего влияния климатических условий на формирование древесных колец отмечалось в научной литератуpe [15].

Анализ показывает, что разные химические элементы (даже выполняющие близкие функции в 
жизнедеятельности клеток) имеют разную временную изменчивость, а значит, потенциально содержат ценную информацию о процессах, определивших их включение в состав клеточных стенок ксилемы. Подход к анализу годичных колец, основанный на детальном изучении их элементного состава, существенно расширяет теоретические и методические возможности дендрохронологии, привлекая данные (для анализа прямого действия и реконструкции) по биогеохимическим условиям произрастания деревьев, с одной стороны, и более детально исследуя роль макро- и микроэлементов в сезонном цикле роста и в формировании тканей древесных растений, с другой. Обнаруженные закономерности изменения концентраций химических элементов в древесных кольцах указывают на перспективность данного подхода для изучения эволюции биогеохимических циклов и подкрепляют перспективное научное направление на стыке дендрохронологии и биогеохимии.

Работа выполнена при подлержке проектов РФФИ, CRDF (RUG1-2950-KR-09, 09-04-92515ИK_a) и программы фундаментальных исследований Президиума Российской Академии наук № 23 (проект № 23.6).

\section{СПИСОК ЛИТЕРАТУРЫ}

1. Taiz L., Zeiger E. Plant Physiology. V Ed. Sunderland; Sinauer Assoc., 2010. 782 p.
2. Ковда В.А. Биогеохимия почвенного покрова. М.:: Наука, 1985. $264 \mathrm{c}$.

3. Vaganov E.A., Hughes M.K., Shashkin A.V. Growth Dynamics of Conifer Tree Rings. B.: 2006. 356 p.

4. Naurzbaev M.M., Vaganov E.A. // J. Geophys. Res. 2000. V. 105. № 6. P. 7317-7327.

5. Grachev A.M., Vaganov E.A., Leavitt S.W., Panyushkina I.P., Chebykin E.P., Shishov V.V., Zhuchenko N.A., Knorre A.A., Hughes M.K., Naurzbaev M.M. // J. Sib. Federal Univ. Biology. 2013. V. 6. № 1. P. 61-72.

6. Agren, G.I., Wetterstedt J.A.M., Billberger M.F.K. // New Phytol. 2012. V. 194. № 4. P. 953-960.

7. Keuper F., van Bodegom P.M., Dorrepaal E., et al. // Glob Change Biol. 2012. V. 18. № 6. P. 1998-2007.

8. Park B.B., Yanai R.D. // Forest Ecol. and Management. 2009. V. 258. № 7. P. 1153-1160.

9. Fromm J. // Tree Physiol. 2010. V. 30. P. 1140-1147.

10. Falkengren-Grerup U., Linnermark N., Tyler G. // Chemosphere. 1985. V. 16. P. 2239-2248.

11. Drouet T.H., Herbauts J., Demaiffe D. // Glob Change Biol. 2005. V. 11. P. 1926-1940.

12. Thimonier A., Dupouey J.L., Le Tacon F. // Ambio. 2000. V. 29. P. 314-321.

13. Knorre A.A., Kirdyanov A.V., Vaganov E.A. // Oecologia. 2006. V. 147. № 2. P. 86-95.

14. Penuelas J., Sardans J., Rivas-Ubach A., Janssens I.A. // Glob. Change Biol. 2012. V. 18. P. 3-6.

15. Goldberg E.L., Zolotarev K.B, Maksimovskaya V.V., Kondratyev V.I., Ovchinnikov D.V., Naurzbaev M.M. // Nucl. Instrum. and Meth. Phys. Res. 2007. V. 575. № 1/2. P. 196-198. 